\title{
A polio intervention in East African refugees to NSW
}

\author{
Mitchell M. Smith ${ }^{\mathrm{A}, \mathrm{C}}$ and Sanjyot Vagholkar ${ }^{\mathrm{B}}$ \\ ${ }^{\mathrm{A}} N \mathrm{SW}$ Refugee Health Service \\ ${ }^{\mathrm{B}}$ General Practice Unit, Fairfield Hospital and School of Public Health and Community Medicine, University of NSW \\ ${ }^{\mathrm{C} C o r r e s p o n d i n g ~ a u t h o r . E m a i l: ~ m i t c h e l l . s m i t h @ s s w a h s . n s w . g o v . a u ~}$
}

\begin{abstract}
This paper summarises a public health intervention in Sydney, NSW in late 2006 that resulted from the potential exposure of a number of refugees to polio virus while in transit in Nairobi, Kenya. The intervention involved the attempted follow-up of 113 persons at risk, assessment for symptoms and immunisation where indicated. No symptomatic cases were found. Seventy-five people were immunised with inactivated poliomyelitis vaccine. The intervention highlighted the importance of close collaboration between health services, the Department of Immigration and Citizenship and settlement service agencies, and provided several lessons to consider when assessing newly arrived refugees.
\end{abstract}

New South Wales (NSW) receives between 3000 and 4000 permanent refugee settlers each year. ${ }^{1}$ In the past 5 years, nearly $43 \%$ of these have come from African countries, in particular the Sudan but also Sierra Leone, Liberia, Burundi and others. ${ }^{1}$

In October 2006, the then Department of Immigration and Multicultural Affairs (DIMA), now known as the Department of Immigration and Citizenship, was notified of a confirmed case of polio in a girl in Dadaab refugee camp in northern Kenya. ${ }^{2}$ A small number of refugees from the Dadaab camp had come to Australia in the period of concern. Additionally, a number of refugees from other camps (mainly in Kenya and Tanzania) had passed through the International Organization for Migration (IOM) Transit Centre in Kilmani, Nairobi, and had potentially been in contact with refugees from the Dadaab region.

A subcommittee of the Communicable Diseases Network of Australia (CDNA) met and, in consultation with DIMA, recommended that refugees who may have come into contact with polio be assessed for signs and symptoms of the disease and be vaccinated if appropriate. A similar intervention was underway in the United States. ${ }^{3}$

In the latter part of 2006, NSW had not received any refugee settlers from Dadaab camp, but received 113 people who had transited through Nairobi in the period in question. It was recognised that not everyone who passed through Nairobi en route to Australia had actually been in the transit camp, so not all were deemed at risk.

\section{Planning}

Advice concerning the intervention was received from CDNA. Refugees who had passed through the transit centre in Nairobi before arrival in Australia would:

- be contacted and given information in their language about the current situation and be asked to attend a clinic for review; 
- be clinically assessed for signs or symptoms of polio and, if indicated, have a stool specimen collected for polio testing;

- have polio vaccination(s) as per age; and

- be given hand washing advice (including a fact sheet from CDNA).

People living in the same household (other than refugee family members) were to be assessed and treated in a similar manner.

DIMA provided advice about the settlement locations of those refugees requiring follow-up. The refugees were dispersed across three area health services as follows:

- Sydney West Area Health Service, 70 refugees;

- Sydney South West Area Health Service, 20 refugees; and

- Wollongong region, South Eastern Sydney Illawarra Area Health Service, 23 refugees.

Ten family units (ranging in size from one to nine people) had arrived under refugee visas (subclass 200) and were therefore in direct contact with the DIMA-funded settlement service, the Australian Centre for Languages (ACL). ${ }^{4,5}$ Eighteen family units had arrived on Special Humanitarian Program visas, having been sponsored: their initial settlement needs were met by family members or other sponsors. ${ }^{4}$ Arrivals in the latter category are historically more difficult to contact and engage.

A teleconference was held on 31 October 2006 between the NSW Department of Health, relevant public health unit directors and the NSW Refugee Health Service with the following outcomes:

- a protocol was drafted outlining roles and responsibilities for public health units, the Refugee Health Service and ACL;

- the Refugee Health Service was tasked with co-ordinating the intervention;

- the Refugee Health Service and each of the three relevant public health units were to consider the most suitable arrangements for local service provision and data collection; and

- no proactive media involvement was planned, for fear of stigmatisation.

The State Vaccine Centre was contacted and it advised that 170 doses of inactivated poliomyelitis vaccine (IPV) were in stock.

\section{Intervention}

A mix of arrangements for service provision was made depending on numbers to be seen and the existing services in each area health service:

\section{Sydney West Area Health Service}

- Clinics (staffed by the public health unit and Refugee Health Service) held at community health centres;

- Existing outpatient clinic for refugee children at the Children's Hospital, Westmead;

- Routine Refugee Health Service clinics; and

- Home visits by public health unit staff.

\section{Sydney South West Area Health Service}

- General Practice Unit, Fairfield Hospital, assisted by public health unit staff;

- General practitioners; and

- Routine Refugee Health Service clinic.

\section{South Eastern Sydney Illawarra Area Health Service}

- General practitioners.

Close liaison was required with ACL to identify current addresses of the refugee settlers, inform them of the need to be assessed and assist with transporting people to the various locations. Immunisation status was assessed through documentation (rarely present) or history.

\section{Outcomes}

DIMA flagged 113 refugees as having come to NSW via Nairobi in the period of interest. Of these, 103 could be contacted. Eighty-five people were confirmed as having passed through the Nairobi IOM Transit Centre between early September and mid October 2006, and were therefore at potential risk of exposure to polio. Characteristics of these 85 people are listed in Table 1 and the numbers of refugees assessed and immunised are shown in Table 2.

None of the refugees who had transited in the Nairobi transit centre had relevant symptoms. Therefore, following the protocol for the intervention, no stool samples were collected. Seventy-five recent arrivals were immunised and 19 household contacts were also assessed and vaccinated.

While the majority of people were seen within 2 weeks of the start of the intervention (i.e. by mid November 2006), difficulties in contacting some refugees and failure of others to attend meant that some individuals were not seen until December. A small number were not contacted (Table 2) despite multiple attempts by ACL staff to locate them by telephone and through community contacts. The 10 people who were not assessed were four young males and one family of six; all were Sudanese entrants on sponsored Special Humanitarian Program visas. People on this visa generally have less engagement with formal settlement services after arrival. 
Table 1. Characteristics of refugees arriving in NSW from the International Organization for Migration Transit Centre in Kilmani, Nairobi assessed for polio $(n=85)$ in 2006

\begin{tabular}{llrr}
\hline & & $N$ & $\%$ \\
\hline \multirow{2}{*}{ Gender } & Males & 47 & 55 \\
Age group (as per vaccine needs) & $<8$ years & 19 & 22 \\
& $8-14$ years & 21 & 25 \\
Citizenship & $15+$ years & 45 & 53 \\
& Sudan & 46 & 54 \\
Residence (area health service) & Burundi & 33 & 39 \\
& Stateless & 6 & 7 \\
& Sydney West & 43 & 51 \\
& South Eastern Sydney Illawarra & 23 & 27 \\
& Sydney South West & 19 & 22 \\
\hline
\end{tabular}

Table 2. Follow-up of refugees to NSW potentially exposed to polio in Nairobi, late 2006

\begin{tabular}{lr}
\hline & N \\
\hline Seen and immunised* & 75 \\
Seen, immunisation up-to-date & 10 \\
Did not transit IOM Transit Centre & 18 \\
Unknown (unable to be contacted) & 10 \\
Total & 113 \\
\hline *Minimum one dose inactivated poliomyelitis vaccine. & \\
IOM:International Organization for Migration. &
\end{tabular}

Other logistic challenges included:

- some new arrivals frequently moving house;

- large families (up to nine people);

- the short timeframe for implementation of the intervention prevented translation of the fact sheets, so information about polio and personal hygiene was given verbally through interpreters or settlement workers who spoke the appropriate language;

- insufficient availability of suitably qualified interpreters;

- transport needs, including the need for staff or volunteers to accompany the refugees to clinics;

- limited capacity of ACL staff to assist due to an ongoing need to assist other new arrivals during the period;

- IPV not being held by general practitioners, requiring transport of the vaccine to general practice clinics; and

- difficulties ascertaining past history of vaccination among the refugees, including a lack of documentation.

The episode did not attract any media attention. This was seen as a positive outcome for the refugee settlers, given that in the past there has been unwarranted concern about refugee settlers and imported infectious diseases. ${ }^{6}$

\section{Discussion}

This was the first time, to our knowledge, that a targeted follow-up of refugee entrants had occurred in NSW in response to a specific disease concern. Despite the logistic challenges outlined, the majority of those needing to be assessed were seen and immunised where appropriate.

The willingness of general practitioners and various hospital, community health and public health unit staff to be involved was vital during this intervention. The NSW Refugee Health Service acted as a central co-ordination point and this was seen as useful, particularly because the Service had existing links with local DIMA staff, settlement service providers, public health units, the General Practice Unit at Fairfield Hospital and other relevant service providers.

A number of lessons were learnt from this public health intervention. In a similar situation in the future, we would recommend:

- direct contact between health service staff and patients in preference to contact via settlement service (e.g. ACL) staff, to help ensure that health information being communicated is appropriate, and to facilitate logistic arrangements;

- that specific additional resources be made available to settlement services for such an intervention, as these services play an important liaison role;

- access to an adequate number of volunteers with suitable transport to get newly arrived refugees to health services efficiently;

- timely efforts at the national level to enhance interpreter availability for certain minority languages;

- increased information for mainstream health staff in this setting to help sensitise them to working with traumatised, newly arrived refugee families;

- more communication in the early stages involving all relevant agencies, which would help to identify logistic barriers and to share potential solutions; and 
- that a detailed protocol covering roles and responsibilities for health and non-health agencies be prepared to assist implementation of the intervention.

The intervention highlighted the fact that even with resource-intensive pursuit of individuals and families, not all newly arrived refugees can necessarily be tracked down. This has implications for other disease outbreaks requiring rigorous follow-up, and for routine screening of certain conditions among new arrivals to NSW.

\section{Conclusion}

This intervention relating to poliomyelitis assessment and immunisation was ultimately successful, yet it presented a number of logistical and other challenges for those involved. It is likely that there will be further interventions of this type in the future, requiring interaction between clinical and public health staff and agencies involved with newly arrived refugees. Lessons from this event may inform the response to similar episodes.

\section{Acknowledgments}

The authors would like to thank medical, nursing and administrative staff from all health services that contributed to this intervention. The support and liaison provided by Dr Kathy King and other staff from the Department of Immigration and Citizenship is appreciated. The vital assistance from ACL settlement service staff is also warmly acknowledged.

\section{References}

1. Australian Government Department of Immigration and Citizenship. New South Wales: settlement trends and needs of new arrivals 2007. Belconnen: Commonwealth of Australia;
2007. Available from: http://www.immi.gov.au/living-inaustralia/delivering-assistance/government-programs/ settlement-planning/_pdf/trends_needs_nsw.pdf (Cited 23 November 2008.)

2. World Health Organization. Wild poliovirus confirmed in Kenya after 22 years. Kenya Weekly Bulletin. Nairobi: World Health Organisation; 2006. Available from: https://www.who. int/hac/crises/ken/sitreps/Kenya_Weekly_Bulletin_15Oct2006. pdf (Cited 23 November 2008.)

3. Centers for Disease Control and Prevention. Recommendations for remaining U.S. bound refugees in Dadaab, Kenya refugee camps following the reported case of poliomyelitis in the camp. Atlanta: Centers for Disease Control and Prevention; 2006. Available from: http://www.cdc.gov/ncidod/dq/refugee/ response/pdf/polio_recs_11_24_06.pdf (Cited 23 November 2008.)

4. Australian Government Department of Immigration and Citizenship. Fact Sheet 60: Australia's Refugee and Humanitarian Program. Canberra: Department of Immigration and Citizenship; 2008. Available from: http://www.immi. gov.au/media/fact-sheets/60refugee.htm (Cited 23 November 2008.)

5. Australian Government Department of Immigration and Citizenship. Fact Sheet 66: Integrated Humanitarian Settlement Strategy. Canberra: Department of Immigration and Citizenship; 2008. Available from: http://www.immi.gov.au/ media/fact-sheets/66ihss.htm (Cited 23 November 2008.)

6. AAP. 'Hanson turns on "diseased" Africans', Sydney Morning Herald, 6 December 2006. Available from: http://www.smh. com.au/news/national/hanson-turns-on-diseased-africans/2006/ 12/06/1165081010724.html (Cited 23 November 2008.) 


\section{The effectiveness of prophylaxis for measles contacts in NSW}

\section{Vicky Sheppeard ${ }^{\mathrm{A}, \mathrm{B}, \mathrm{F}}$, Bradley Forssman ${ }^{\mathrm{C}}$, Mark J. Ferson' ${ }^{\mathrm{D}}$, Conrad Moreira ${ }^{\mathrm{B}}$, Sue Campbell-Lloyd ${ }^{\mathrm{A}}$, Dominic E. Dwyer ${ }^{\mathrm{E}}$ and Jeremy M. McAnulty ${ }^{\mathrm{A}}$}

ACentre for Health Protection, NSW Department of Health

${ }^{\mathrm{B}}$ Centre for Population Health, Sydney West Area Health Service

${ }^{C}$ School of Public Health, University of Sydney

DPublic Health Unit, South Eastern Sydney Illawarra Area Health Service and School of Public Health and Community Medicine, University of NSW

${ }^{\mathrm{E}}$ Centre for Infectious Diseases and Microbiology Laboratory Services, Institute of Clinical Pathology and Medical Research, Westmead Hospital

${ }^{\mathrm{F} C o r r e s p o n d i n g}$ author. Email: vicky.sheppeard@ swahs.health.nsw.gov.au measles vaccine was first made available for infants. ${ }^{1} \mathrm{~A}$ second dose was introduced in New South Wales (NSW) for adolescent girls in 1992 and for boys in 1994. Since 1999, the vaccine has been recommended for children at 12 months and 4 or 5 years of age combined with mumps and rubella vaccine (MMR). In 1998, a school-based catch-up program provided a second MMR dose to primary school children. ${ }^{2}$ By 2005 , measles notifications in Australia had declined to the lowest ever recorded, and the NSW vaccination coverage rate was stable at around $94 \%$ for first dose and $89 \%$ for two doses. ${ }^{3}$

Measles is a notifiable condition in NSW, and public health follow-up involves interviews with the affected person or carer, advice about minimising spread to others, identification of exposed contacts, and provision of prophylactic immunisation, using either measles-containing vaccine (within 72 hours of exposure) or normal human immunoglobulin (NHIG) within 7 days of exposure. ${ }^{4}$ Measles may be infectious for many days before the diagnosis is made therefore many people may be exposed. Public health follow-up can be resource intensive but there are few data to indicate its effectiveness, and practice varies from country to country.

Recent analyses published by the United States (US) Centers for Disease Control and Prevention have confirmed the effectiveness of NHIG when given as post-exposure prophylaxis (PEP) at a dose of $0.25 \mathrm{~mL} / \mathrm{kg}$ up to 6 days after contact; however, one case occurred from those given MMR as prophylaxis., 5 A review in Japan raised some concerns regarding the efficacy of NHIG in children when used at a dose of $0.33 \mathrm{~mL} / \mathrm{kg}$ up to 5 days after exposure. ${ }^{7}$ We used the opportunity of measles outbreaks during March, April and May 2006 to assess the effectiveness of PEP. ${ }^{8}$

\section{Methods}

We obtained data on all notified cases of measles onset between 1 March and 31 May 2006 in NSW residents. We also included data on two residents of other states who acquired measles in NSW and required public health control activities by NSW public health units.

After a virtual absence of endemic measles transmission in Australia for 3 years, a large outbreak began in Sydney in March 2006. Measles vaccination rates in Australia have gradually increased since 1968, when single dose
Consistent with national recommendations, we defined a case as either laboratory-confirmed (either detection of measles-specific immunoglobulin $\mathrm{M}(\mathrm{IgM})$ antibodies in 
the presence of a compatible clinical illness, or detection of measles virus by immunofluorescence (IF) or reverse transcriptase-polymerase chain reaction (RT-PCR) or measles virus culture); or clinical (fever and/or cough and/or coryza and/or conjunctivitis and maculopapular rash) with an epidemiological link to a laboratory-confirmed case. ${ }^{4}$ All measles-specific IgM antibody tests were either performed initially or confirmed at a reference laboratory. Measles virus IF was performed on acetone-fixed smear swabs stained with measles-specific monoclonal antibodies and RT-PCR using primers to the measles nucleoprotein region on nasal or pharyngeal specimens, as previously described. ${ }^{9}$

Surveillance officers collected data on symptoms and signs of cases through interview of cases (or their parents) and their health-care providers, and recorded on a standard reporting form. Case interviews were also used to identify possible contacts.

A contact, as defined in the NSW Health protocol, was anyone who was in the same room as the case, or the same room for up to 2 hours after, during the infectious period. ${ }^{4}$ All contacts included in this study were Australian residents. Susceptible contacts, i.e. people who were considered to have inadequate immunity to measles, were defined according to Australian guidelines as:

- infants from 6-12 months of age;

- children aged 1-4 years who had not received any doses of MMR; and

- children aged over 4 years, and adults born during or after 1966, who had not received two doses of MMR. ${ }^{10}$

Contacts identified as susceptible were offered postexposure prophylactic immunisation with either MMR within 3 days of exposure, or NHIG within 7 days of exposure.

Other public health actions included:

- advising contacts about the symptoms of measles and how to avoid infecting other people;

- utilising mass media messages;

- enhanced surveillance using direct communication via faxes to general practitioners, hospitals, child-care centres and laboratories to raise awareness of the outbreak; and

- extension of eligibility for free MMR vaccine from general practitioners to all susceptible persons in NSW from 18 May 2006.

Data on cases, contacts and prophylaxis were collated using Microsoft Excel 2000 (Microsoft Corporation).
Prophylaxis effectiveness (PE) was calculated using the cohort method:

$$
\mathrm{PE}=((\mathrm{ARU}-\mathrm{ARP}) / \mathrm{ARU}) \times 100)
$$

where ARU represents the attack rate in susceptible contacts not receiving prophylaxis and ARP is the attack rate in susceptible contacts who received prophylaxis. ${ }^{11}$ Taylor series 95\% confidence intervals were calculated around the relative risk, and then converted to PE confidence intervals. $^{12}$

Rates of secondary cases in contact groups were compared using Fisher's exact test in EpiInfo 3.5.1 (Centers for Disease Control and Prevention).

\section{Results}

\section{Description of the outbreak}

Fifty-seven cases of measles were reported during the 3-month period (Figure 1). A description of the first 2 months of the outbreak has been reported elsewhere. ${ }^{8,13}$

Of the 57 cases, four (7\%) were aged under 1 year, 19 (33\%) 1-4 years, 14 (25\%) 5-14 years, 18 (32\%) 15-40 years and $2(4 \%)$ over 40 years. Thirteen $(23 \%)$ required hospitalisation. Hospital admission was more common in infants and adults (38\%) than in children aged $1-14$ years $(12 \%)$.

\section{Public health interventions}

In total, 1760 contacts were identified, an average of 31 contacts per case. Five hundred and fifty-three contacts (31\%) were defined as susceptible to measles. Twelve patients spent time in busy hospital emergency departments while infectious and prior to being diagnosed, resulting in 1139 of these identified contacts.

Early in the outbreak, delays in clinical and laboratory confirmation of measles and case notification as well as delays in identification of potential contacts, meant that prophylactic immunisation for contacts within the recommended 7 days of exposure was often not possible. ${ }^{4}$ For example, an early case visited the hospital emergency department four times prior to diagnosis, and 120 families who were exposed were not identified within 7 days.

Table 1 summarises prophylactic administration for susceptible contacts and numbers of secondary cases according to prophylaxis type. Other contacts managed by their general practitioner or hospital are not included.

Of the 265 contacts known to have received prophylaxis, only two $(0.8 \%)$ subsequently developed measles. Both of these contacts received NHIG on the seventh day following contact with a case. Of the 288 susceptible contacts who did not receive any prophylaxis, 13 (4.5\%) developed 


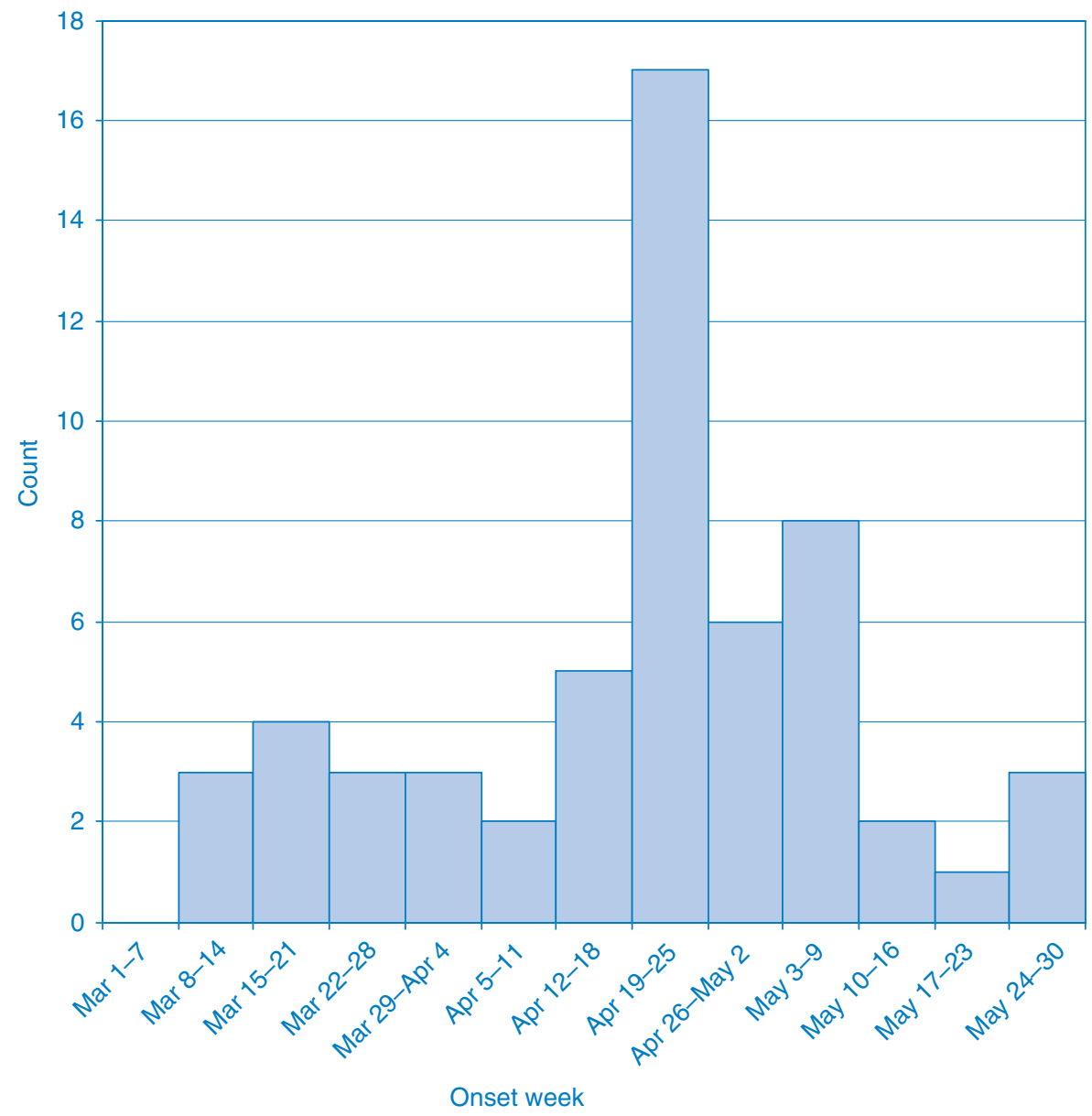

Figure 1. Notified cases by week of onset, NSW, March-May 2006.

Table 1. Prophylaxis and outcomes for susceptible contacts of measles cases, NSW, March-May 2006

\begin{tabular}{lccc}
\hline & $\begin{array}{c}\text { Contacts } \\
\text { identified }\end{array}$ & $\begin{array}{c}\text { Secondary cases } \\
\text { identified }\end{array}$ & $\begin{array}{c}\text { Rate } \\
\text { (per 1000) }\end{array}$ \\
\hline MMR & 82 & 0 & 0 \\
NHIG & 183 & 2 & 10.9 \\
Refused & 93 & 3 & 32.3 \\
Too late & 195 & 10 & 51.3 \\
Total & 553 & 15 & 27.1 \\
\hline \multicolumn{4}{l}{ MMR: measles-mumps-rubella vaccine. } \\
NHIG: normal human immunoglobulin.
\end{tabular}

measles. Applying this percentage to the 265 contacts known to have received prophylaxis, 12 (rather than two) may have otherwise developed measles.

The effectiveness of receiving either MMR or NHIG as prophylaxis compared to no prophylaxis in susceptible contacts was $83.3 \%$ (95\% CI: 27-96). The effectiveness of prophylaxis with NHIG alone was 75.8\% (CI: 0-94) and for MMR was $100 \%$.
The rate of secondary measles was significantly higher among social contacts (eight cases from 117 identified contacts) and household contacts (five from 128) compared to either of the two cases that arose from 1139 identified hospital contacts, and none from 400 school or child-care contacts $(P<0.0002)$.

\section{Discussion}

In the largest outbreak of measles in NSW since the National Measles Control Campaign, public health interventions including post-exposure prophylaxis were effective in preventing the further spread of measles. Although perhaps only 10 secondary cases were directly averted, those additional 10 cases could have generated further generations of cases and their contacts.

This study had a number of limitations. First, contacts' susceptibility was estimated based on Australian guidelines and were not serologically confirmed. Classification on the basis of age could lead to either an over- or underestimation of the number of susceptible contacts. Our data on the rate of measles in contacts who did not receive prophylaxis suggest that perhaps as few as $4.5 \%$ of contacts 
who we defined as susceptible were in fact susceptible, and so the number of contacts categorised as susceptible was likely an overestimate. Any misclassification was, however, non-differential between those who did and did not receive prophylaxis, which would result in an underestimate of effectiveness. Second, the estimation of effectiveness may be affected by under enumeration of secondary cases. It is possible that secondary cases of measles were not detected if they did not seek health care or were misdiagnosed. However, we believe this is unlikely due to the assertive public health actions. Finally, we did not record data on all contacts as some contact tracing efforts were managed outside of public health units.

Despite these limitations, this study has demonstrated that PEP was effective in reducing this measles outbreak, and is likely to be so in the future. Such outbreaks have been predicted because a proportion of the population remains susceptible to measles. ${ }^{14,15}$ Each year, 5-10\% of eligible Australian children are not vaccinated, there is an expected vaccine failure rate and a known susceptibility in young adults born after 1965.16 The success of Australia's measles vaccination programs has largely resulted in the elimination of local transmission of measles in the past decade. ${ }^{3}$ Thus, health-care providers and the community are less familiar with its presentation, severity and potential for complications. This presents a challenge in maintaining a high index of suspicion for measles diagnosis (including appropriate laboratory confirmation) and ensuring an appropriate outbreak response from both health-care providers and the community. Therefore, a timely response by public health agencies to every measles notification is critical to effective measles control.

We estimated that the effectiveness of prophylaxis with either NHIG or MMR was $83 \%$, and that both types of prophylaxis were effective. When MMR was given within 3 days of exposure, no cases of measles occurred. Measles did arise in two recipients of NHIG but both of these contacts received prophylaxis on the seventh day after exposure. This suggests that the effectiveness of NHIG prophylaxis decreases with time since a contact is exposed to measles, and may not be useful more than 6 days after exposure.

There are only a small number of recent reports on the value of prophylaxis during measles outbreaks. In an outbreak in Iowa, United States, no cases of measles arose in 20 contacts given NHIG prophylaxis within 6 days of contact with measles; however, one case arose among 175 persons receiving post-exposure MMR. ${ }^{5}$ In an outbreak in Japan, NHIG appeared to be less effective as $57 \%$ of contacts given NHIG developed measles. ${ }^{7}$

The apparently greater effectiveness of prophylaxis in the Iowa and NSW outbreaks may be due to the dose of NHIG used for measles prevention: the recommended NHIG dose for measles prophylaxis in Australia is $0.2 \mathrm{~mL} / \mathrm{kg}$ and $0.25 \mathrm{~mL} / \mathrm{kg}$ in the US, whereas in Japan $0.33 \mathrm{~mL} / \mathrm{kg}$ of NHIG is used. ${ }^{4,7,17}$ However, the reported titre of measlesspecific IgG in the Japanese NHIG was equal to or less than $16 \mathrm{IU} / \mathrm{mL}$, while the titre of measles-specific $\mathrm{IgG}$ in the Australian NHIG preparation is currently estimated to be $32 \mathrm{IU} / \mathrm{mL}$ (personal communication, Trish Kleeman, CSL Limited, 19 April 2007). This suggests that if a high level of immunity is maintained in the community then adequate measles antibody titres will be present in NHIG preparations derived from blood donations.

\section{Conclusion}

Measles outbreaks create a substantial burden on the public health system. In the recent outbreak in Iowa, the economic impact of containing one case of measles was estimated at \$US142 452, largely in time spent by public health staff on contact tracing and giving prophylaxis. ${ }^{6}$

In our study, 176 contacts were traced and 26 people given post-exposure prophylaxis for each case of measles averted. Although only 10 secondary cases of measles may have been averted, many subsequent generations of disease and the follow-up of scores of associated contacts were also likely to have been prevented.

Post-exposure immunisation remains an effective tool for preventing secondary cases of measles.

\section{Acknowledgments}

The NSW Public Health Network, particularly communicable disease surveillance officers, the Virology Section of the Institute for Clinical Pathology and Medical Research and NSW Department of Health Communicable Diseases Branch and Immunisation Unit all contributed extensively. Alex Rosewell assisted with the review of emergency department records to identify the index patient.

\section{References}

1. Gidding HF, Burgess MA, Kempe AE. A short history of vaccination in Australia. Med J Aust 2001; 174: 37-40.

2. Turnbull FM, Burgess MA, McIntyre PB, Lambert SB, Gilbert GL, Gidding HF et al. The Australian Measles Control Campaign, 1998. Bull World Health Organ 2001; 79: 882-8.

3. Brotherton J, Wang H, Schaffer A, Quinn H, Menzies R, Hull B et al. Vaccine preventable diseases and vaccination coverage in Australia 2003 to 2005. Commun Dis Intell 2007; 31(Suppl): S31-6.

4. NSW Department of Health. Measles response protocol for public health units. Sydney: NSW Department of Health; 2004. Available from http://www.health.nsw.gov.au/infect/ pdf/measles.pdf (Cited 20 March 2006.)

5. Centers for Disease Control and Prevention. Postexposure prophylaxis, isolation, and quarantine to control an importassociated measles outbreak - Iowa, 2004. MMWR Morb Mortal Wkly Rep 2004; 53: 969-71.

6. Dayan GH, Ortega-Sanchez IR, LeBaron CW, Quinlisk MP. The cost of containing one case of measles: The Economic 
Impact on the Public Health Infrastructure - Iowa, 2004. Pediatrics 2005; 116: e1-4. doi:10.1542/peds.2004-2512

7. Endo A, Izumi H, Miyashita M, Taniguchi K, Okubo O, Harada K. Current efficacy of postexposure prophylaxis against measles with immunoglobulin. J Pediatr 2001; 138: 926-8. doi:10.1067/mpd.2001.113710

8. Department of Health and Aging. Communicable Diseases Surveillance - Highlights for 2nd quarter, 2006. CDI 2006; 30(3): 385-7. Available from: http://www.health.gov.au/ internet/main/publishing.nsf/Content/cda-cdi3003n.htm (Cited November 2008.)

9. Weston KM, Dwyer DE, Ratnamohan M, McPhie K, Chan SW, Branley JM et al. Nosocomial and community transmission of measles virus genotype D8 by a returning traveller from Nepal. Commun Dis Intell 2006; 30: 58-65.

10. Communicable Diseases Network Australia and New Zealand. Guidelines for the control of measles outbreaks in Australia. Technical Report Series No. 5. Canberra: Commonwealth Department of Health and Aged Care; 2000.

11. Torvaldsen S, McIntyre PB. Observational methods in epidemiologic assessment of vaccine effectiveness. Commun Dis Intell 2002; 26: 451-7.
12. Hightower AW, Orenstein WA, Martin SM. Recommendations for the use of Taylor series confidence intervals for estimates of vaccine efficacy. Bull World Health Organ 1988; 66: 99-105.

13. Communicable Diseases Report. New South Wales, for March and April 2006. NSW Public Health Bull 2006; 17: 88-94. doi:10.1071/NB06022

14. MacIntyre CR, Hull B, Burgess M. Measles control in NSW Divisions of General Practice. NSW Public Health Bull 2003; 14: 13-6. doi:10.1071/NB03004

15. Parker AA, Staggs W, Dayan GH, Ortega-Sánchez IR, Rota PA, Lowe L et al. Implications of a 2005 measles outbreak in Indiana for sustained elimination of measles in the United States. N Engl J Med 2006; 355: 447-55. doi:10.1056/NEJMoa060775

16. Gidding HF, Gilbert GL. Measles immunity in young Australian adults. Commun Dis Intell 2001; 25: 133-6.

17. Heyman DL, editor. Control of communicable diseases manual. 18th ed. Washington: American Public Health Association; 2004. 


\section{Audit of post-exposure treatment to prevent lyssavirus infection in Sydney South West Area Health Service, 2005-2007}

\section{Adam T. Craig ${ }^{\mathrm{A}, \mathrm{C}}$, Trish F. Mannes ${ }^{\mathrm{B}}$ and Leena Gupta ${ }^{\mathrm{B}}$}

ANSW Public Health Officer Training Program, NSW Department of Health

BPublic Health Unit, Sydney South West Area Health Service

${ }^{\mathrm{C}}$ Corresponding author. Email:

adam.craig@doh.health.nsw.gov.au

\begin{abstract}
Objectives: To describe the profile of people who received post-exposure treatment to prevent lyssavirus infection in Sydney South West Area Health Service between 2005 and 2007 and to assess treatment compliance with the current NSW Health protocol. Methods: Thirty-eight public health files and a subset of 11 medical records were reviewed to collect demographic, exposure and treatment information for the period. Results: Twenty-nine (76\%) potential Lyssavirus exposures occurred overseas. Nine potential exposures occurred within Australia; eight of these resulted from a bat bite or scratch. Thirteen (34\%) of all potential exposures resulted from handling an animal. Conclusion: Many potential exposures were the result of a bite or scratch from a domesticated animal; the animal's survival or health status was not routinely recorded. While all people who commenced post-exposure treatment completed the prescribed course, this was often not within the stipulated timeframe.
\end{abstract}

Lyssavirus is a zoonotic viral disease that generally infects domestic and wild mammals. The genus Lyssavirus falls within the family Rhabdoviridae. There are seven genotypes recognised within the genus (although a number of other viruses await classification). These are rabies virus; Lagos bat virus; Mokola virus; Duvenhage virus; the European bat lyssaviruses 1 and 2; and Australian bat lyssavirus (ABLV). ${ }^{1-3}$
Lyssavirus is typically transmitted to humans in the virusladen saliva of an infected animal through a bite, scratch or lick on broken skin or mucous membranes. ${ }^{1-3}$ Symptoms of lyssavirus infection include: headache; fever; malaise; sensory change around the site of the bite or scratch; weakness; excitability; aversion to air and water; delirium; convulsions; and coma. Once symptoms of lyssavirus infection develop, death usually follows within 2 to 6 days. $^{3}$ An estimated 55000 deaths per year are caused by lyssavirus genotype 1 (rabies) worldwide, mostly in rural areas of Asia and Africa. Asia carries the largest public health burden, with an estimated 24000 deaths per year. ${ }^{4}$

While lyssavirus genotype 1 (rabies) has never been reported in Australia, ABLV has emerged as an important reservoir for the disease. ABLV rarely infects humans and only two cases of human infection have been recorded in Australia. Both cases occurred in the mid 1990s and were fatal. ${ }^{5-7}$ People who handle Australian fruit bats (Pteropus sp.) are at risk of contracting $\mathrm{ABLV}$, whereas those who come into contact with unvaccinated domestic or wild animals in countries where lyssavirus 1 is endemic are at risk of contracting rabies. ${ }^{3}$ In more than $99 \%$ of all human lyssavirus 1 cases worldwide, the virus has been transmitted from a dog. ${ }^{8}$

The most effective mechanism to aid in the protection against Lyssavirus is to wash the wound site immediately for a minimum of 15 minutes with soap or detergent and water, followed by the application of an antiviral antiseptic such as ethanol $(70 \%)$, iodine or providone iodine. ${ }^{3,9-11}$ For people not previously vaccinated against Lyssavirus, post-exposure treatment consists of five intramuscular injections of $1 \mathrm{~mL}$ rabies vaccine at days $0,3,7,14$ and 28-30, and one dose of human rabies immunoglobulin (HRIG) at the time of the first post-exposure vaccine. It is recommended that as much of the HRIG as possible be infiltrated into the wound site. For people who have had previous vaccination against Lyssavirus, post-exposure treatment consists of two doses of vaccine at day 0 and day $3 \cdot^{3,8,9,12}$

In New South Wales (NSW), public health units are responsible for authorising all post-exposure treatment, in accordance with the Rabies and Other Lyssavirus Infections Response Protocol for NSW Public Health 
Units. $^{3}$ This paper describes the profile of people who received post-exposure treatment in Sydney South West Area Health Service (SSWAHS) between 2005 and 2007, and assesses if treatment was delivered in accordance with the current NSW Health protocol.

\section{Methods}

We extracted the public health records for notifications of potential exposure to Lyssavirus received by the SSWAHS Public Health Unit between 1 January 2005 and 31 May 2007, and collected de-identified patient demographic information and exposure data. One-third of the extracted files were randomly selected and the patients' medical records were accessed from either their general practitioners or the hospitals that provided the post-exposure treatment. We collected information from the medical records about the nature of the exposure and adherence to treatment. We verified the information collected from the public health records. We were unable to obtain medical records for two cases. Data was extracted by AC (author) and collated and analysed using Microsoft Excel.

The audit was approved by the human research ethics committee of Royal Prince Alfred Hospital.

\section{Results}

From 1 January 2005 to 31 May 2007, the SSWAHS Public Health Unit received notifications and recommended post-exposure treatment for 38 people (18 males and 20 females), potentially exposed to Lyssavirus. Seventeen of these were for people potentially exposed in 2005, 17 in 2006 and four in the first 5 months of 2007. Fifty-three percent were aged between 21 and 40 years.

Of the 38 people who sought post-exposure treatment, 29 (76\%) were potential exposures while overseas and nine (24\%) while in Australia. Of the 29 potential overseas exposures, 12 were exposed in Thailand; three in China and two each in India, Vietnam, Malaysia and the Philippines. Five of the remaining six people were potentially exposed in South-East Asian countries.

Dog bites $(n=15,54 \%)$ and dog scratches $(n=5,15 \%)$ were the most common form of potential overseas exposure. Other potential overseas exposures were associated with bites or scratches from monkeys ( $n=6,21 \%)$, cats $(n=2,7 \%)$ and one mouse $(3 \%)$. The World Health Organization does not recommend post-exposure treatment of potential exposure to rabies associated with mouse bite or scratch. ${ }^{13}$ Bites or scratches from domesticated animals accounted for $16(55 \%)$ potential overseas exposures; 13 of these were from domesticated dogs. Nondomestic animals accounted for 12 (41\%) potential overseas exposures; six from wild dogs and four from wild monkeys (Table 1). Of those potentially exposed while overseas, six (21\%) people reported that they had handled the animal that bit or scratched them.

Of the nine potential exposures occurring in Australia, eight were the result of a wild bat bite or scratch and one bite was from a vaccinated dog imported from Italy.

Seven (78\%) of the people potentially exposed in Australia reported that they handled the animal that caused the injury. The injuries occurred when handling, releasing, detangling or assisting a bat (Table 1). No records were available about the health of the animal in the days following the potential exposure and no records indicated that any of the animals were tested for Lyssavirus.

Of the 11 randomly selected medical records reviewed to assess compliance with post-exposure treatment, three people commenced post-exposure treatment on the day of exposure, three within 7 days of exposure, one on the eighth day and one 33 days after potential exposure. The three other records reported commencement of treatment while overseas and within a week of potential exposure. All 11 people completed the full five-dose course of postexposure treatment; five within the 30-day period stipulated in the Response Protocol for NSW Public Health Units, three within 40 days of exposure and three completed the course more than 50 days after exposure. ${ }^{3}$ Three people received HRIG within a week of exposure, three did not receive HRIG at all and no record was available to determine if HRIG was provided to the other five patients.

\section{Discussion}

This audit provides a useful description of people receiving post-exposure treatment to prevent lyssavirus infection in SSWAHS and supports the findings of similar work undertaken by Young et al. in Queensland. ${ }^{14}$ The audit was able to identify risk behaviours that contribute to potential exposure to Lyssavirus, both in Australia and overseas. Of note is the number of people $(n=13,34 \%)$ who were exposed when handling the animal that bit or scratched them, in particular people exposed to bat bites or scratches in Australia $(n=5,56 \%)$. Simple strategies to mitigate this exposure, such as not engaging with animals or use of personal protective equipment in occupational settings, may reduce the incidence of potential exposure.

Fifty percent of all exposures were a result of bite or scratch from a domesticated animal. As an animal's survival (or health status) is a clear indicator of infection, the collection of this information can inform the risk assessment and subsequent treatment, particularly for those seeking post-exposure treatment weeks after being potentially exposed. The World Health Organization recommends ceasing post-exposure treatment if the animal remains healthy throughout an observation period of 10 days or if the animal is euthanised and found to be negative for 
Table 1. Demographic and exposure details of people potentially exposed overseas and in Australia to rabies/lyssavirus in Sydney South West Area Health Service, Jan 2005 to May 2007

\begin{tabular}{|c|c|c|c|c|c|c|}
\hline & \multicolumn{2}{|c|}{$\begin{array}{l}\text { Potentially exposed } \\
\text { overseas }\end{array}$} & \multicolumn{2}{|c|}{$\begin{array}{c}\text { Potentially exposed in } \\
\text { Australia }\end{array}$} & \multicolumn{2}{|c|}{ Total } \\
\hline & $N$ & $\%$ & $N$ & $\%$ & $N$ & $\%$ \\
\hline \multicolumn{7}{|l|}{ Demographics } \\
\hline Male & 16 & 55 & 2 & 22 & 18 & 47 \\
\hline Female & 13 & 45 & 7 & 78 & 20 & 53 \\
\hline Persons & 29 & 100 & 9 & 100 & 38 & 100 \\
\hline \multicolumn{7}{|l|}{ Age } \\
\hline $0-20$ & 2 & 7 & 1 & 11 & 3 & 8 \\
\hline $21-40$ & 17 & 59 & 3 & 33 & 20 & 53 \\
\hline $41-60$ & 5 & 17 & 2 & 22 & 7 & 18 \\
\hline $61-80$ & 4 & 14 & 1 & 11 & 5 & 13 \\
\hline$>80$ & 1 & 3 & 1 & 11 & 2 & 5 \\
\hline \multicolumn{7}{|l|}{ Animal } \\
\hline Dog & 20 & 69 & $1^{*}$ & 11 & 21 & 55 \\
\hline Bat & 0 & 0 & 8 & 89 & 8 & 21 \\
\hline Monkey & 6 & 21 & 0 & 0 & 6 & 16 \\
\hline Cat & 2 & 7 & 0 & 0 & 2 & 5 \\
\hline Mouse & 1 & 3 & 0 & 0 & 1 & 3 \\
\hline \multicolumn{7}{|l|}{ Domestication of animal } \\
\hline Non-domestic & 12 & 41 & 8 & 89 & 20 & 53 \\
\hline Domestic & 16 & 55 & 1 & 11 & 17 & 45 \\
\hline Unknown & 1 & 3 & 0 & 0 & 1 & 3 \\
\hline \multicolumn{7}{|l|}{ Wound type } \\
\hline Bite & 18 & 62 & 5 & 56 & 23 & 61 \\
\hline Scratch & 6 & 21 & 3 & 33 & 9 & 24 \\
\hline Unknown & 5 & 17 & 1 & 11 & 6 & 16 \\
\hline \multicolumn{7}{|l|}{ Engaged with animal } \\
\hline Yes & 6 & 21 & 7 & 78 & 13 & 34 \\
\hline No & 22 & 76 & 1 & 11 & 23 & 61 \\
\hline Unknown & 1 & 3 & 1 & 11 & 2 & 5 \\
\hline \multicolumn{7}{|l|}{ First aid at time of exposure } \\
\hline Cleaned with soap/water & 18 & 62 & 7 & 78 & 26 & 68 \\
\hline Cleaned at health care facility & 6 & 21 & 0 & 0 & 6 & 16 \\
\hline None administered & 2 & 7 & 2 & 22 & 4 & 11 \\
\hline Unknown & 3 & 10 & 0 & 0 & 3 & 8 \\
\hline
\end{tabular}

Data source: Sydney South West Public Health Unit files and patients' medical records.

*Potentially exposed from an imported canine.

rabies. ${ }^{9}$ For potential exposures from bats in Australia, national guidelines state that where possible the bat should be kept and tested for Lyssavirus at an appropriate reference laboratory. ${ }^{10}$

People who sought post-exposure treatment for Lyssavirus generally did so soon after being exposed and completed the course of treatment, but not always within the timeframe stipulated in the NSW Health protocol. Emphasis on adherence to treatment and mechanisms to follow up patients and health-care providers to facilitate timely delivery of treatment may be required to improve compliance with the protocol in the future.
The value of this audit is limited by the small number of cases available to review and the quality of information in medical and public health records about the treatment rationale, follow-up, previous treatment (if post-exposure treatment commenced elsewhere) or the factors contributing to the potential exposure. Due to these limitations, we note that the findings of the audit should be interpreted with caution and recommend its replication in other area health services or on a statewide basis to gain a better understanding of the issue. In addition, our study only reflects circumstances where post-exposure treatment was requested and does not include potentially exposed people who did not seek treatment. 


\section{Conclusion}

This study used routinely collected data to review potential exposures to Lyssavirus and compliance with the NSW Health treatment protocol for people seeking post-exposure treatment in SSWAHS. The audit identified that: many potential exposures to Lyssavirus were the result of a bite or scratch from a domesticated animal; an animal's survival or health status at the time of the potential exposure or afterwards is not routinely recorded; and all people who commenced post-exposure treatment completed the prescribed course, although not always within the timeframe stipulated in the protocol.

\section{References}

1. NSW Health. Rabies and bat lyssavirus infection. N SW Public Health Bull 2002; 13(1-2): 27.

2. World Health Organization Media Centre. Fact Sheet - Rabies. Geneva: World Health Organization; 2008. Available from: http://www.who.int/mediacentre/factsheets/fs099/en/ (Cited 14 November 2008.)

3. NSW Health. Rabies and other lyssavirus infections: response protocol for NSW Public Health Units, Notifiable Diseases Manual. Sydney: NSW Health; July 2007. Available from: http://www.health.nsw.gov.au/factsheets/guideline/rabies.html (Cited 14 November 2008.)

4. WHO Expert. Consultation on Rabies: First Report. WHO Technical Report Series 931. Geneva: World Health Organization; 2005. Available from: http://www.who.int/rabies/ trs931_\%2006_05.pdf (Cited 14 November 2008.)

5. Hanna J, Carney I, Smith G, Tannenberg A, Deverill J, Botha J et al. Australian Bat Lyssavius infection: a second human case with long incubation period. Med J Aust 2000; 172(12): 573-4.
6. Allworth A, Murray K, Morgan J. A human case of encephalitis due to a lyssavirus recently identified in fruit bats. $C D I$ 1996; 20(24): 504.

7. NSW Health. Infectious Disease Factsheet. Rabies and Bat Lyssavirus Infection. Sydney: NSW Health; 2008. Available from: http://www.health.nsw.gov.au/factsheets/infectious/ rabiesbatinfection.html (Cited 14 November 2008.)

8. National Health and Medical Research Council. The Australian Immunisation Handbook. 9th edition. Canberra: NHMRC and Australian Government Department of Health and Ageing; 2008. pp. 110-7.

9. World Health Organization. WHO Recommendations on Rabies Post-Exposure Treatment and the Correct Technique of Intradermal Immunization Against Rabies. Geneva: WHO; 1996. Available from: http://whqlibdoc.who.int/hq/1996/ WHO_EMC_ZOO_96.6.pdf (Cited 14 November 2008.)

10. Commonwealth Department of Health and Ageing. Australian Bat Lyssavirus Information for Medical Practitioners. Canberra: Commonwealth Department of Health and Ageing; 2001.

11. Rabies vaccine-update. Wkly Epidemiol Rec 2007; 82(8): $62-8$.

12. Wilde H. Failure of post exposure rabies prophylaxis. Vaccine 2007; 25(44): 7605-9. doi:10.1016/j.vaccine.2007.08.054

13. World Organization for Animal Health. Health Standards. Manual of Diagnostic Tests and Vaccines for Terrestrial Animals. Chapter 2.2.5. Rabies. Paris: World Organization for Animal Health; 2007. Available from: http://www.oie.int/Eng/ Normes/Mmanual/A_00044.htm (Cited 14 November 2008.)

14. Young M, McCall B. Trends in potential exposure to Australian bat lyssavirus in South East Queensland, 1996 to 2003.

Commun Dis Intell 2004; 28(2): 258-60. 


\section{Another opportunity for prevention: assessing alcohol use by women attending breast screening services in Lismore, NSW}

\author{
Michelle D. Daly ${ }^{\mathrm{A}, \mathrm{C}}$, Megan E. Passey ${ }^{\mathrm{B}}$ \\ and Amanda J. Harvey ${ }^{\mathrm{A}}$ \\ ANorth Coast Area Health Service \\ ${ }^{\mathrm{B}}$ Department of Rural Health (Northern Rivers), \\ School of Public Health, University of Sydney \\ ${ }^{\mathrm{C}}$ Corresponding author. Email: \\ Michelle.Daly@ncahs.health.nsw.gov.au
}

Substantial epidemiological evidence supports the association between alcohol consumption and the risk of breast cancer; however, information on alcohol consumption is not routinely collected by breast screening services in NSW. This study was conducted to investigate the level of self-reported alcohol use among women accessing North Coast BreastScreen in Lismore, NSW. Two hundred and sixty-four consecutive women were screened using the Alcohol Use Disorders Identification Test. Their drinking status was categorised as low risk, risky or high risk. Two-thirds of the screened women $(69.7 \%)$ were classified as low-risk drinkers; $9.8 \%$ as risky and $0.4 \%$ as high-risk drinkers. Although the risk of breast cancer increases with the amount of alcohol consumed, evidence suggests that even low-risk drinking is associated with increased risk of breast cancer. Implications for prevention activities by breast screening services are discussed.

As part of its routine program, BreastScreen New South Wales (NSW) assesses women for breast cancer risk factors. Alcohol use is not currently assessed in any BreastScreen NSW service, despite substantial evidence supporting the association between alcohol consumption and the risk of breast cancer. ${ }^{1-4}$ Consumption of $30 \mathrm{~g}$ of alcohol each day (three standard drinks) is associated with a similar level of risk to other recognised risk factors for breast cancer, such as young age at menarche and family history; however, alcohol consumption is one of the few risks that is modifiable. ${ }^{2}$

The current National Health and Medical Research Council (NHMRC) guidelines note that alcohol increases women's risk of breast cancer and the risk increases with the level of alcohol used. Compared with women who drink little or no alcohol, the risk of breast cancer is $35 \%$ higher in women who drink three to four standard drinks a day and $67 \%$ with more than four drinks a day. Even low level drinking is associated with some increase in risk. ${ }^{4}$

The 2004 National Drug Strategy Household Survey found that just over half (58.1\%) of women aged 60 years or more approved of regular (i.e. daily or nearly every day) alcohol use. Approval for regular drinking in younger age groups was higher, with $74.7 \%$ of $40-49$-year-old women and $69 \%$ of 50-59-year-old women approving of regular drinking. The survey also showed that in the Australian adult female population, 9.6\% used alcohol at a level considered to be risky or high risk for long-term harm from a range of chronic physical and psychological illnesses. ${ }^{5}$

BreastScreen services are free to eligible women and the uptake is high, with $63.5 \%$ of women aged $45-54$ years, $80.9 \%$ of women aged $55-64$; and $84.2 \%$ of $65-74-$ year-old women reporting having received a screening mammogram in the previous 2 years. ${ }^{6}$ For the North Coast region of NSW, the corresponding figures are $73.1 \%$, $81.9 \%$ and $80.5 \%$ respectively. ${ }^{6}$ We conducted a study to assess the level of self-reported alcohol use among women accessing North Coast BreastScreen.

\section{Methods}

The receptionist or a women's health nurse invited consecutive women attending North Coast BreastScreen in Lismore NSW to participate in a study. They were informed that the purpose of the study was a survey on alcohol use. Those providing written informed consent were asked to complete a brief anonymous questionnaire that included the Alcohol Use Disorders Identification Test (AUDIT) assessment tool and basic demographic information.

The AUDIT is a brief 10-item screening instrument developed by the World Health Organization for detecting risky and high-risk levels of drinking. ${ }^{7}$ It has been used widely 
and validated as a screening tool in more than 16 studies, including Australian studies. ${ }^{7-11}$ It uses three domains: alcohol intake; dependence; and problems associated with drinking. Based on the scores, it classifies respondents' alcohol use into three drinking risk levels: low risk (includes non-drinkers), risky and high risk. For women, low-risk drinking is classified as scoring $0-5$ on the AUDIT; risky drinking is a score of 6-12; and high-risk drinking is a score of 13 or more. ${ }^{7}$

Data were collected one day per week over three consecutive months in 2006. Women were given information on the study and, if willing to participate, were asked to provide consent. Participants were given written instructions on how to complete and self-score the survey. They were also given written feedback on their AUDIT score, options for interventions and other relevant information. All women were able to complete the AUDIT while waiting to have their mammogram, without assistance from the researchers. No women asked to speak with a clinician to discuss their drinking risk level. Women were instructed to separate their consent form and AUDIT and place them in two separate envelopes to ensure anonymity.

Data were entered onto a specifically designed database. Based on the AUDIT score, women were categorised as nondrinkers, low-risk drinkers, risky or high-risk drinkers.

Ethical approval for the study was obtained from the North Coast Area Health Service Human Research Ethics Committee.

\section{Results}

Two hundred and sixty-four women completed the AUDIT questionnaire. No women declined to participate. Fiftythree women $(20.1 \%)$ were classified as non-drinkers, 184 $(69.7 \%)$ as low-risk drinkers, $26(9.8 \%)$ as risky drinkers and one $(0.4 \%)$ as a high-risk drinker (Table 1$)$. All but four of the women classified as risky or high-risk drinkers drank alcohol at least two to three times per week, with 12 reporting drinking four or more times per week. Nearly a quarter of the women reported drinking at least three or four drinks on a typical day when they were drinking.

\section{Discussion}

In this study, we found that $10.2 \%$ of women attending North Coast BreastScreen reported risky or high-risk drinking, when screened using the AUDIT. This is lower than the rates reported for the NSW Population Health Survey (2006). ${ }^{6}$ However, the definitions of risky drinking used in the two studies are different. We used the AUDIT, which has been widely validated for use as a screening tool in clinical settings, with the intention of providing interventions for those identified as drinking at risky levels. By contrast, the NSW Population Health Survey uses a definition appropriate for population surveys and defines
Table 1. Age and alcohol consumption for 264 consecutive women attending North Coast BreastScreen, Lismore, NSW, over 3 months in 2006

\begin{tabular}{|c|c|c|}
\hline & $n$ & $\%$ \\
\hline \multicolumn{3}{|l|}{ Age (years) ${ }^{a}$} \\
\hline $40-49$ & 14 & 5.4 \\
\hline $50-59$ & 134 & 51.3 \\
\hline $60-69$ & 102 & 39.1 \\
\hline $70+$ & 11 & 4.2 \\
\hline \multicolumn{3}{|c|}{ Frequency of alcohol consumption } \\
\hline Never & 53 & 20.1 \\
\hline Monthly or less & 62 & 23.5 \\
\hline 2-4 times a month & 42 & 15.9 \\
\hline 2-3 times a week & 51 & 19.3 \\
\hline 4 or more times a week & 56 & 21.2 \\
\hline \multicolumn{3}{|c|}{$\begin{array}{l}\text { Number of alcoholic drinks on } \\
\text { a typical day }\end{array}$} \\
\hline 1 or 2 (or less) & 203 & 76.9 \\
\hline 3 or 4 & 53 & 20.1 \\
\hline 5 or 6 & 7 & 2.7 \\
\hline 7 to 9 & 1 & 0.4 \\
\hline 10 or more & 0 & 0 \\
\hline \multicolumn{3}{|l|}{ Risk level (AUDIT score) } \\
\hline Non-drinker & 53 & 20.1 \\
\hline Low risk $(0-5)$ & 184 & 69.7 \\
\hline Risky (6-12) & 26 & 9.8 \\
\hline High risk (>13) & 1 & 0.4 \\
\hline
\end{tabular}

risky drinking for women as one of the following: drinking alcohol on a daily basis; drinking on average more than two standard drinks per day; or drinking more than four standard drinks on any one day. High-risk drinking was determined as drinking seven or more standard drinks on any one day as per NHMRC Australian Alcohol Guidelines. ${ }^{4}$ With the AUDIT, women drinking every day but at low levels would not be classified as risky drinkers. Thus use of the drinking levels defined in AUDIT results in a more conservative estimate of the prevalence of risky drinking.

The prevalence of risky drinking is consistent with the level of acceptability of alcohol use reported in the 2004 National Drug Strategy Household Survey. ${ }^{5}$ This result may reflect a lack of awareness of the association between alcohol use and breast cancer. The Breast Health Survey found that $31.1 \%$ of women considered there was no increased risk of breast cancer associated with alcohol consumption. ${ }^{12}$

Given the prevalence of risky drinking among women in the breast screening age group, and that alcohol consumption is a modifiable risk factor for breast cancer, it would be beneficial for primary health-care services such as 
BreastScreen to implement routine screening and early intervention. Completion of the AUDIT screening tool without any clinician feedback has itself been shown to be an effective brief intervention and is therefore more beneficial than merely providing women with information on the risks associated with alcohol use and breast cancer. ${ }^{13}$ Completion of the AUDIT encourages women to reflect on their drinking level. The NSW Health clinical guidelines for nursing and midwifery practice in NSW support a selfhelp model of intervention when staff lack time to provide a more intensive intervention. ${ }^{14}$ The guidelines add that self-help approaches are effective with women who drink at mild and moderate levels. However, it would be beneficial to conduct further research on the effectiveness of this approach in the BreastScreen setting.

In our study, we were able to incorporate the use of the AUDIT into the daily screening procedures of North Coast BreastScreen, with no women refusing to participate. Women were given information on how to complete and self-score the survey, feedback on their score and options for interventions, including contact details for drug and alcohol services. As BreastScreen has the mandate to screen all women aged 50-70 years for breast cancer, the service routinely sees the majority of women in this age group. Screening and provision of feedback in a manner similar to that used in this study by all NSW BreastScreen services would be an inexpensive mechanism for identifying women at risk and alerting women to the risks associated with alcohol consumption. Delivering this intervention would also support the role of general practitioners who provide early interventions in primary care.

The NHMRC recently released new draft guidelines for safe alcohol consumption, which suggested reducing the level of alcohol consumption that is considered safe. These new guidelines reinforce the argument for incorporating screening for alcohol use, with provision of suitable interventions, into the routine procedures of BreastScreen services.

\section{Acknowledgments}

We would like to thank the staff of Lismore BreastScreen Services and the women who participated in the study.

\section{References}

1. Singletary K, Gapstur S. Alcohol and breast cancer: review of epidemiologic and experimental evidence and potential mechanisms. JAMA 2001; 286(17): 2143-51. doi:10.1001/jama.286.17.2143
2. Smith Warner SA, Hunter D, Yaun S-S, Walter C, Potter J, Holmberg $\mathrm{L}$ et al. Alcohol and breast cancer in women. JAMA 1998; 279(7): 535-40. doi:10.1001/jama.279.7.535

3. National Health and Medical Research Council. Australian alcohol guidelines for low risk drinking: Draft for public consultation. Canberra: NHMRC; 2007. Available from: http://www.nhmrc.gov.au/guidelines/_files/draft_australian_ alcohol_guidelines.pdf (Cited 20 March 2009.)

4. National Health and Medical Research Council. Australian Alcohol Guidelines: Health Risks and Benefits. Endorsed October 2001. Canberra: Commonwealth of Australia; 2003. Available from: http://www.nhmrc.gov.au/publications/ synopses/_files/ds9.pdf (Cited 20 March 2009.)

5. Australian Institute of Health and Welfare. 2004 National Drug Strategy Household Survey: Detailed Findings. AIHW cat. no. PHE66. Canberra: AIHW (Drug Statistics Series No. 16); 2005.

6. Population Health Division. The health of the people of New South Wales: Report of the Chief Health Officer, 2006. Sydney: NSW Department of Health; 2006.

7. Saunders JB, Aasland OG, Babor TF, De La Fuente JR, Grant M. Development of the alcohol use disorders identification test (AUDIT): WHO collaborative project on early detection of persons with harmful alcohol consumption. Addiction 1993; 88: 791-804. doi:10.1111/j.1360-0443.1993.tb02093.x

8. Saunders JB, Aasland OG, Amundsen A, Grant M. Alcohol consumption and related problems among primary health care patients. WHO collaborative project on early detection of persons with harmful alcohol consumption. Addiction 1993; 88: 349-62. doi:10.1111/j.1360-0443.1993.tb00822.x

9. WHO Brief Interventions Study Group. A cross-national trial of brief interventions with heavy drinkers. Am J Public Health 1996; 86: 949-55.

10. Conigrave KM, Hall W, Saunders JB. The AUDIT questionnaire: choosing a cut-off score. Addiction 1995; 90: 1349-56. doi:10.1111/j.1360-0443.1995.tb03552.x

11. Conigrave KM, Saunders JB, Reznik RB. Predictive capacity of the AUDIT questionnaire for alcohol-related harm. Addiction 1995; 90: 1479-85. doi:10.1111/j.13600443.1995.tb02810.x

12. National Breast Cancer Centre. National Breast Cancer Centre Breast Health Survey Technical Report. 2005. Camperdown: NBCC; 2005.

13. Babor TF, Grant M. A randomized clinical trial of brief interventions in primary health care: summary of WHO project. Addiction 1994; 89: 657-60. doi:10.1111/j.13600443.1994.tb00944.x

14. NSW Department of Health. Clinical guidelines for nursing and midwifery practice in NSW: identifying and responding to drug and alcohol issues. NSW Health, 2007. 


\section{Pertussis outbreaks in aged-care facilities}

\section{The Editor}

NSW Public Health Bulletin

\section{Dear Editor}

We concur with Al-Murieb and colleagues that pertussis outbreaks are a potential and probably under-recognised problem in aged-care facilities. ${ }^{1}$ In February 1999, we investigated an outbreak of acute respiratory infection, which had affected over $50 \%$ of the residents of a Sydney nursing home. Serological and virological testing pointed to influenza A as the major cause of illness in 19 of 35 coughing residents. ${ }^{2}$ However, 10 residents also had evidence of recent pertussis infection based on the presence in serum of IgA antibodies to Bordetella pertussis detected using an in-house, whole-cell antigen assay, which has been shown not to cross-react with sera containing elevated antibody titres to influenza A virus. ${ }^{3}$ Of these 10 residents, one demonstrated seroconversion to Bordetella IgA on parallel testing of serum samples collected during the outbreak and 7 months earlier. ${ }^{2}$

Single-sample serological assays have been the mainstay of laboratory diagnosis of pertussis in adults, but recently concerns about poor specificity of some of these assays have been reported. ${ }^{3,4}$ The rapid advance of nucleic acid detection technology has meant that polymerase chain reaction (PCR) assays of high specificity have become widely available in public and private sector pathology laboratories for the diagnosis of pertussis. Early in the infection, the sensitivity of PCR is superior to that of culture; however, this sensitivity, like that of culture, rapidly decreases as the paroxysmal phase progresses. ${ }^{5}$ In Australia in the period 2000-2005, PCR seems to have almost replaced culture in the diagnosis of pertussis in infants and young children, while serology was the means of diagnosis in 80-90\% of cases in adults. ${ }^{6}$ Single-sample Bordetella serology has a definite place in the evaluation of a coughing illness that has lasted a number of weeks, especially in adults; however, in the setting of an outbreak investigation where cough symptoms have been present for less than 3-4 weeks, PCR should be considered the first line in laboratory diagnosis, if it is available.

\section{Mark J. Ferson}

Public Health Unit, South Eastern Sydney Illawarra Area Health Service and School of Public Health and Community Medicine, University of NSW

\section{Peter W. Robertson}

SEALS Area Serology Laboratory, Prince of Wales Hospital and School of Medical Sciences, University of NSW

\section{References}

1. Al-Murieb A, Brown AM, Raulli A, George C, Gander C, Forrester $\mathrm{P}$ et al. Evidence of pertussis clusters in three agedcare facilities in the former Macquarie Area Health Service, NSW. N SW Public Health Bull 2008; 19: 157-60. doi:10.1071/NB07054

2. Ferson MJ, Morgan K, Robertson PW, Hampson AW, Carter I, Rawlinson WD. Concurrent summer influenza and pertussis outbreaks in a nursing home in Sydney, Australia. Infect Control Hosp Epidemiol 2004; 25: 962-6. doi:10.1086/502327

3. Robertson PW, Goldberg H, Jarvie BH, Smith DD, Whybin LR. Bordetella pertussis infection: a cause of persistent cough in adults. Med J Aust 1987; 146: 522-5.

4. Public Health Laboratory Network. Pertussis case definition. Canberra: Commonwealth of Australia, 2007. Available from: www.health.gov.au/internet/main/publishing.nsf/Content/cdaphlncd-pertussis.htm (Cited 30 December 2008.)

5. de Melker HE, Versteegh FG, Conyn-Van Spaendonck MA, Elvers LH, Berbers GA, van Der Zee A et al. Specificity and sensitivity of high levels of immunoglobulin $G$ antibodies against pertussis toxin in a single serum sample for diagnosis of infection with Bordetella pertussis. Clin Infect Dis 1999; 29: 1239-42.

6. Quinn HE, McIntyre PB. Pertussis epidemiology in Australia over the decade 1995-2005 - trends by region and age group. Commun Dis Intell 2007; 31: 205-15.

\section{The Editor}

\section{NSW Public Health Bulletin}

\section{Dear Editor}

Ferson and Robertson have pointed out that polymerase chain reaction (PCR) has become, if not the gold standard, at least a silver standard for the diagnosis of pertussis. They recommend that in an outbreak situation of a coughing illness where symptoms have been present for less than 3-4 weeks, PCR should be considered in first-line laboratory diagnosis if it is available. We entirely concur.

In the outbreak in rural NSW in 2004 that we reported, there was little access to timely PCR testing for pertussis. Laboratories encouraged single-point specific IgA assays, 
which could be performed locally (or at least regionally), rather than PCR, which was not readily available.

In our investigation, we were concerned about the use of single-point specific IgA because interpretation can be difficult. We used a case definition of positive single-point IgA and a clinically compatible illness. This definition proved to be a robust epidemiological diagnosis.

Around the same time, cases of pertussis were identified in other workplaces. A few of these workplaces responded by asking staff to have a blood test (against our advice). A number of completely asymptomatic people had positive single-point specific IgA, which was not considered evidence of current pertussis infection.
It is interesting to note that pathological testing in the current pertussis epidemic is almost entirely PCR. In the face of large numbers of cases, many general practitioners seem content to make a clinical diagnosis of pertussis, particularly if there is some epidemiological link, and to treat appropriately.

Outbreaks of pertussis continue to occur in institutions and workplaces supporting the need for booster vaccination of adults.

Anthony M. Brown and Ala'a Al-Murieb

Population Health Division, Greater Western Area Health Service 


\section{Equine influenza}

\section{Paula J. Spokes ${ }^{\mathrm{A}}$, Ian Roth and Paul K. Armstrong $\mathrm{C}$}

A NSW Public Health Officer Training Program, NSW Department of Health

${ }^{\mathrm{B}} N S W$ Department of Primary Industries

${ }^{\mathrm{C}}$ Biopreparedness Unit, NSW Department of Health

Equine influenza (EI) is an acute viral respiratory disease of horses and other equine species such as donkeys and mules. Symptoms generally include elevated temperature, a deep dry cough and nasal discharge. ${ }^{1,2} \mathrm{EI}$ is highly infectious and serious outbreaks associated with the importation of horses with subclinical infection from endemic areas have occurred in South Africa, Asia and Europe in recent years. ${ }^{3,4}$ The virus is usually transmitted by respiratory secretion droplets through the cough of an infected horse and can survive on skin, fabrics and surfaces of contaminated equipment for up to 24 hours. ${ }^{5}$ Further spread by direct transmission from humans and fomites can subsequently be significant. ${ }^{5}$

Prior to 2007, there were no reported cases of EI in Australia and vaccination against the disease was not practised other than to meet export requirements. Following reports of suspected infection at the Eastern Creek Quarantine Station in New South Wales (NSW), the first reports of EI disease in Australia were made to the NSW Department of Primary Industries by a veterinarian who observed sick horses in Sydney on 24 August 2007. Laboratory testing confirmed that these horses were infected with EI. A statewide lockdown of the movement of horses was declared on 25 August by the NSW Chief Veterinary Officer and the Australian Veterinary Emergency Plan (AUSVETPLAN) equine influenza strategy for disease control was activated. ${ }^{5}$ At the peak of this outbreak, 47000 infected horses on 5943 properties were reported in NSW and, as a result, horse owners across Australia experienced significant economic and social impacts.

Measures taken to control and eradicate the disease included: quarantine and controlled movement of horses; establishment of disease control zones; implementation of decontamination procedures for properties; introduction of surveillance systems to determine the extent of infection, vaccination and awareness; and information campaigns for industry and the wider community. The response to EI involved over 2000 people deployed across NSW as part of a whole-of-government approach. ${ }^{6}$ The response was ultimately successful with Australia declaring freedom from EI on 30 June 2008.

\section{NSW Health involvement}

Epidemiologists, public health nurses, surveillance officers and trainee public health officers from the NSW Department of Health and area health services provided technical advice and assistance to the Department of Primary Industries from September to December 2007. During this time, a number of disease cluster investigations were initiated to determine the mode of transmission for cases of EI that had no apparent epidemiological links, and to study the role of fomite and other modes of virus transmission. One such study, conducted in October 2007, concluded that direct transmission of EI virus via bird plumage or other animals was possible. ${ }^{7}$ Further research would be necessary to confirm the possibility of this transmission mechanism.

\section{Influenza: horses and humans}

While there are similarities between horse and human influenza outbreak management strategies, there are also significant differences in strategies used to control the spread of the diseases.

The Biopreparedness Unit, NSW Department of Health, is responsible for developing procedures for the management of large scale human disease outbreaks in NSW, focussing on pandemic influenza planning. The response for pandemic influenza in NSW aims to contain the spread of infection until a vaccine becomes available. The stock standstill strategy, effective in the containment of EI, would be extremely difficult to replicate for the control of a human influenza outbreak. The objective of such a strategy is to eliminate the transmission outside of the restricted zone, thereby allowing the infection to 'burn itself out'. Similar, but less severe, strategies for humans in an influenza pandemic include isolation, quarantine, social distancing and movement restrictions. More severe restrictions such as isolation of communities or regions would have unacceptably high social and financial costs.

NSW Health involvement in the response to the EI emergency was invaluable in providing insight into the potential challenges of a large-scale human disease outbreak such as pandemic influenza.

This example of a large-scale disease outbreak response highlights the importance of planning for the success of disease control strategies. Important considerations for future pandemic planning include an understanding of the mechanisms for disease transmission and the resource 
and personnel capacity required to respond to a statewide outbreak.

\section{References}

1. Huntingdon PJ. Equine influenza: the disease and its control. Technical report series No. 184. Melbourne: Department of Agriculture and Rural Affairs, Victoria; 1990.

2. Miller WC. Equine influenza: further observations on the "coughing" outbreak, 1965. Vet Rec 1965; 77(16): 455-6.

3. Dalglish AR. The International Movement of Horses: The current infectious disease situation. Proceedings of the 9th International Conference of Racing Analysts and Veterinarians. New Orleans, USA, 1992.

4. Guthrie AJ, Stevens KB, Bosman PP. The circumstances surrounding the outbreak and spread of equine influenza in South Africa. Rev Sci Tech 1999; 18(1): 179-85.
5. Animal Health Australia. Disease strategy: Equine influenza (Version 3.0). Australian Veterinary Emergency Plan (AUSVETPLAN), Edition 3. Canberra: Primary Industries Ministerial Council; 2007.

6. NSW Department of Primary Industries. Summary of the 2007/08 Equine Influenza Outbreak. Sydney: NSW Department of Primary Industries; 2008. Available from: http://www.dpi.nsw.gov.au/agriculture/livestock/horses/health/ general/influenza/summary-of-the-200708-ei-outbreak (Cited 20 March 2009.)

7. Spokes P, Marich A, Musto J, Ward K, Craig A, McAnulty J. Investigation of equine influenza transmission in NSW: walk, wind or wing? N S W Public Health Bull 2009; In press. 


\section{Influenza}

\section{What is influenza?}

Influenza (or 'the flu') is caused by infection with influenza viruses $\mathrm{A}, \mathrm{B}$ and rarely $\mathrm{C}$. It mainly affects the throat and lungs, but can also cause problems with the heart and rest of the body, especially in people with other health problems. Influenza viruses regularly change, causing epidemics each winter in New South Wales. Every few decades a new type of influenza virus will emerge causing a severe and widespread epidemic (or pandemic).

\section{What are the symptoms?}

Symptoms usually occur 1-3 days after infection, and may include sudden onset of fever, headache, muscle and joint pain, sore throat, cough, runny or stuffy nose and severe tiredness. Most people recover within a week. Compared with many other infections (like the common cold), influenza tends to cause more severe symptoms and complications, which can include pneumonia, heart failure or worsening of other illnesses.

\section{How is it spread?}

The virus is mainly spread from person to person through droplets after an infected person coughs or sneezes, or through touching (e.g. when a person shakes hands with another). It is easier to catch influenza in confined or crowded spaces. A person with influenza is contagious from the day before, until a few days after symptoms begin.

\section{Who is at risk?}

Anyone can get influenza. Elderly people, those with other illnesses (such as heart disease, lung disease or diabetes) and small children are more likely to develop complications.

\section{How is it prevented?}

Anyone older than 6 months who wishes to avoid influenza should visit their general practitioner for a vaccination each year, before winter begins. Influenza vaccination is especially recommended for:

- adults aged 65 years and older

- Aboriginal and Torres Strait Islander people aged 15 years or older

- adults and children older than 6 months with chronic diseases affecting the heart, lungs, or that require regular medical follow up

- persons with certain neurological conditions

- persons with immunodeficiency, including human immunodeficiency virus (HIV) infection

- residents of nursing homes and other long-term care facilities
- homeless people and those who care for them

- adults and children older than 6 months who live in a household with a person who fits into any of the categories above

- health care workers

- staff, volunteers and frequent visitors of nursing homes and long-term care facilities

- people involved in the commercial poultry industry or in culling poultry during confirmed avian influenza activity

- people providing essential services

- children (6 months to 10 years) on long-term aspirin therapy

- people planning to visit parts of the world where influenza is circulating

- women who will be in the second or third trimester of pregnancy (even if already pregnant) between June and October.

It is important to note that:

- Children up to the age of 9 years require two doses at least 1 month apart in the first year they are vaccinated.

- It will take up to 2 weeks for the body to develop immunity after vaccination. The vaccine is designed to match the viruses likely to be circulating that winter. In otherwise healthy adults, the vaccine usually provides about $70-90 \%$ protection against infection for about 1 year.

- The vaccine is not recommended for some people, including those with allergies to eggs or who have had anaphylaxis following a previous dose of influenza vaccine or any vaccine component.

- Side effects can include soreness at the vaccination site, fever, fatigue and muscle soreness.

- The vaccine contains killed virus and so cannot cause influenza.

- People with a fever should delay vaccination until recovered.

- People who have previously had Guillain-Barré Syndrome should discuss vaccination with their doctor.

The vaccine is available free of charge to people aged 65 years or older and to Aboriginal or Torres Strait Islander people aged 50 years or older or aged 15 to 49 years with a chronic illness.

\section{How is it diagnosed?}

Based on symptoms and examination, a doctor can diagnose an influenza-like illness. The diagnosis of influenza can only be confirmed by testing a sample of the fluid from the back of the nose and throat, or a sample of blood. These tests are usually only needed if the illness is part of an outbreak, is unusually severe or there are complications. 


\section{How is it treated?}

Fever, headaches and muscle pains can be relieved with paracetamol and rest. Medications for influenza (oseltamivir and zanamivir) can reduce the severity and the duration of illness if taken within 2 days of the first symptoms. They are available only on prescription and are sometimes in short supply.

\section{What is the public health response?}

Laboratories must confidentially notify cases of influenza to the local public health unit. NSW Health also monitors the incidence of influenza in the community by tracking the number of people presenting to selected clinics with influenza-like illness, and the number of laboratory samples submitted to selected laboratories.

For more information please contact your doctor, local public health unit or community health centre.

This fact sheet is available at: http://www.health.nsw. gov.au/factsheets/infectious/influenza.html

\section{NSW}




\section{Communicable Diseases Report, NSW, March and April 2009}

\section{Communicable Diseases Branch NSW Department of Health}

For updated information, including data and facts on specific diseases, visit www.health.nsw.gov.au and click on Public Health then Infectious Diseases, or access the site directly at: http://www.health. nsw.gov.au/public health/infectious/index.asp.

Figure 1 and Tables 1 and 2 show reports of communicable diseases received through to the end of April 2009 in New South Wales (NSW).

\section{Respiratory diseases H1N1 influenza 09 (human swine influenza)}

The first cases of human swine influenza were reported in Mexico and North America during April 2009. Subsequent spread to several other countries has prompted the World Health Organization to raise the pandemic alert level to five (out of a possible six). The situation is evolving rapidly and intense public health control measures are in place.

\section{Seasonal influenza}

Seasonal influenza will appear in NSW this winter regardless of whether H1N1 influenza 09 emerges in Australia. The severity of seasonal influenza outbreaks depends on several factors including: how different the circulating strain is to the strains that circulated in previous years (few people in the community will have sufficient immunity to a new strain); how well the strains in the vaccine are matched to the circulating strain; the proportion of the population that is vaccinated; and other characteristics of the virus.

\section{Invasive meningococcal disease}

Thirteen cases of invasive meningococcal disease were reported in March and April in NSW, bringing the total number of cases to 23 so far this year. There were 12 cases in the same period in 2008.

\section{Legionnaires' disease}

Fifteen cases of Legionnaires' disease were notified in March and April in NSW. Of these, eight were due to L. pneumophila infection (acquired from environmental sources such as water droplets), six were due to L. longbeachae (acquired from environmental sources such as soils) and one was not specified. The cases were unrelated. Twenty-six cases of Legionella infection have been notified in NSW so far this year, compared with 89 for the same period in 2008 .

\section{Vaccine-preventable diseases Pertussis (whooping cough)}

The pertussis outbreak continued in NSW with 3069 cases notified with onset in March and April. In 2008, a total of 8851 cases were notified, and in 2007 only 2099 cases were notified. Comparison of data over time must be undertaken with caution, however, due to recent changes in the use of diagnostic technologies (including the increasing use of nucleic acid testing), as well as changes in case ascertainment over time (related to increased awareness of the disease among doctors and the broader community).

A 4-week-old infant from the NSW North Coast died from pertussis in early March. The infant was admitted to hospital a week earlier following onset of the illness. While deaths from pertussis are rare, there were six child fatalities in NSW during an outbreak in the mid-to-late 1990s.

Timely immunisation of infants is important as unvaccinated infants are at highest risk of infection and at high risk of complications. Because pertussis immunity wanes over time, many older children and adults are susceptible to infection and can be the source of new infections in infants.

For a limited time in NSW, free pertussis (dTpa) vaccine will be available for all new parents, couples who are planning a pregnancy, grandparents and any other adults who will regularly care for infants less than 12 months of age.

General practitioners should:

- Check the immunisation status of new parents and other children and provide catch-up vaccination.

- Offer free dTpa vaccine to new parents, grandparents and any other adults who regularly care for infants. 
- Consider vaccinating infants at 6 weeks if the opportunity arises. Infanrix-hexa, Prevenar and Rotarix are all licensed for use in infants from 6 weeks of age. The next scheduled vaccines should be given at 4 and 6 months of age.

\section{Measles}

Two cases of measles were notified in March and April in NSW, bringing the total for the year so far to eight. Thirtynine cases were notified in 2008. The majority of measles cases notified so far this year have been in young people recently returned from overseas travel, or in their contacts.

Many people born between 1966 and 1980 remain susceptible to measles because most people in this age group have not been exposed to measles infection and those who were routinely immunised typically received only one measles vaccine. Two doses are required to provide high level protection. Anyone born after 1965 should ensure that they have had two doses of Measles-Mumps-Rubella vaccine, unless they know they are immune.

\section{Tetanus}

One case of tetanus was notified in an unimmunised overseas traveller, bringing the total for the year to date to two.

While uncommon, tetanus can be fatal. Tetanus vaccine is given at 2, 4 and 6 months of age, with boosting doses at 4 years, between 15 and 17 years, and again at 50 years. In recent years, cases in NSW have tended to be older Australian-born women. A likely explanation for this is that childhood vaccination only became available after World War II and predominantly male military personnel received vaccination during service.

Opportunistically reviewing and updating vaccinations of older Australians and people born in developing countries, who may have missed out on childhood vaccination, as well as managing tetanus-prone wounds in people of all ages contributes to prevention of this disease.

\section{Enteric diseases \\ Cryptosporidiosis}

A large outbreak of cryptosporidiosis peaked in March, with 411 laboratory-confirmed cases notified in NSW. A further 201 reported cases in April bring the year to date total to 612 , which exceeds the total of 484 cases reported in 2008 .

\section{Salmonellosis}

Cases of laboratory-confirmed Salmonella infection were above seasonal expectations in the first 3 months of 2009, with 608 cases notified in March and April in NSW. The largest increases occurred in S. Typhimurium, phage typed as 170. Investigations into some recent outbreaks have suggested the source of infection to be poor handling of contaminated food, including eggs. Raw eggs have previously been linked to multiple outbreaks of salmonellosis.

\section{Shigellosis}

Thirty-eight laboratory-confirmed cases of Shigella infection were notified in March and April in NSW, compared with 14 for the same period in 2008 .

\section{Gastroenteritis}

In March and April, 48 outbreaks of gastroenteritis were notified in institutional settings in NSW, affecting a total of 613 people. Of these, 15 were in aged-care facilities, five in hospitals, 26 in child care centres, one in a school and one in a mental health facility. The majority of these outbreaks appear to have been caused by viral infections, spread by person-to-person transmission.

Clinical specimens were submitted for testing from 17 suspected person-to-person gastroenteritis outbreaks. Norovirus was confirmed in stool samples from patients in five outbreaks. In one outbreak, Clostridium perfringens was considered a probable cause. This number of outbreaks is typical of this time of year.

There were eight suspected foodborne outbreaks in March and April in NSW, affecting 232 people. Of these, six were outbreaks of salmonellosis, one of which was linked to consumption of deep-fried ice cream.

\section{Other conditions \\ Community acquired methicillin-resistant \\ Staphylococcus aureus}

Methicillin-resistant Staphylococcus aureus is an ongoing concern both in health care settings and in the general community.

Many healthy people carry staphylococcal bacteria on their skin and in their nose. Some strains of S. aureus, known as methicillin-resistant Staphylococcus aureus (MRSA), are resistant to methicillin and other antibiotics. Within this group, some strains, known as Community acquired MRSA (CaMRSA), are more likely to spread within the community rather than in health care settings. CaMRSA infections can manifest as pimples and boils, impetigo or cellulitis, osteomyelitis, bacteraemia and pneumonia.

Two new factsheets have been developed to assist clinicians, public health practitioners and others to help manage patients with CaMRSA:

http://www.health.nsw.gov.au/factsheets/infectious/staph_ aureus.html

http://www.health.nsw.gov.au/factsheets/guideline/ methicillin_res_stap.html 
Figure 1. Reports of selected communicable diseases, NSW, January 2004 to April 2009, by month of onset.

Preliminary data: case counts in recent months may increase because of reporting delays.

Laboratory-confirmed cases only, except for measles, meningococcal disease and pertussis.

BFV, Barmah Forest virus infection; RRV, Ross River virus infection; lab conf, laboratory confirmed;

Men $\mathrm{Gp} C$ and $\mathrm{Gp} \mathrm{B}$, meningococcal disease due to serogroup $C$ and serogroup $B$ infection;

other/unk, other or unknown serogroups.

NB: Multiple series in graphs are stacked, except gastroenteritis outbreaks.

NB: Outbreaks are more likely to be reported by nursing homes and hospitals than by other institutions.

\begin{tabular}{|lr|}
\hline \multicolumn{2}{|c|}{ NSW Population } \\
Male & $50 \%$ \\
$<5$ y & $7 \%$ \\
$5-24$ y & $27 \%$ \\
$25-64$ y & $53 \%$ \\
$65+y$ & $13 \%$ \\
Rural & $46 \%$ \\
\hline
\end{tabular}

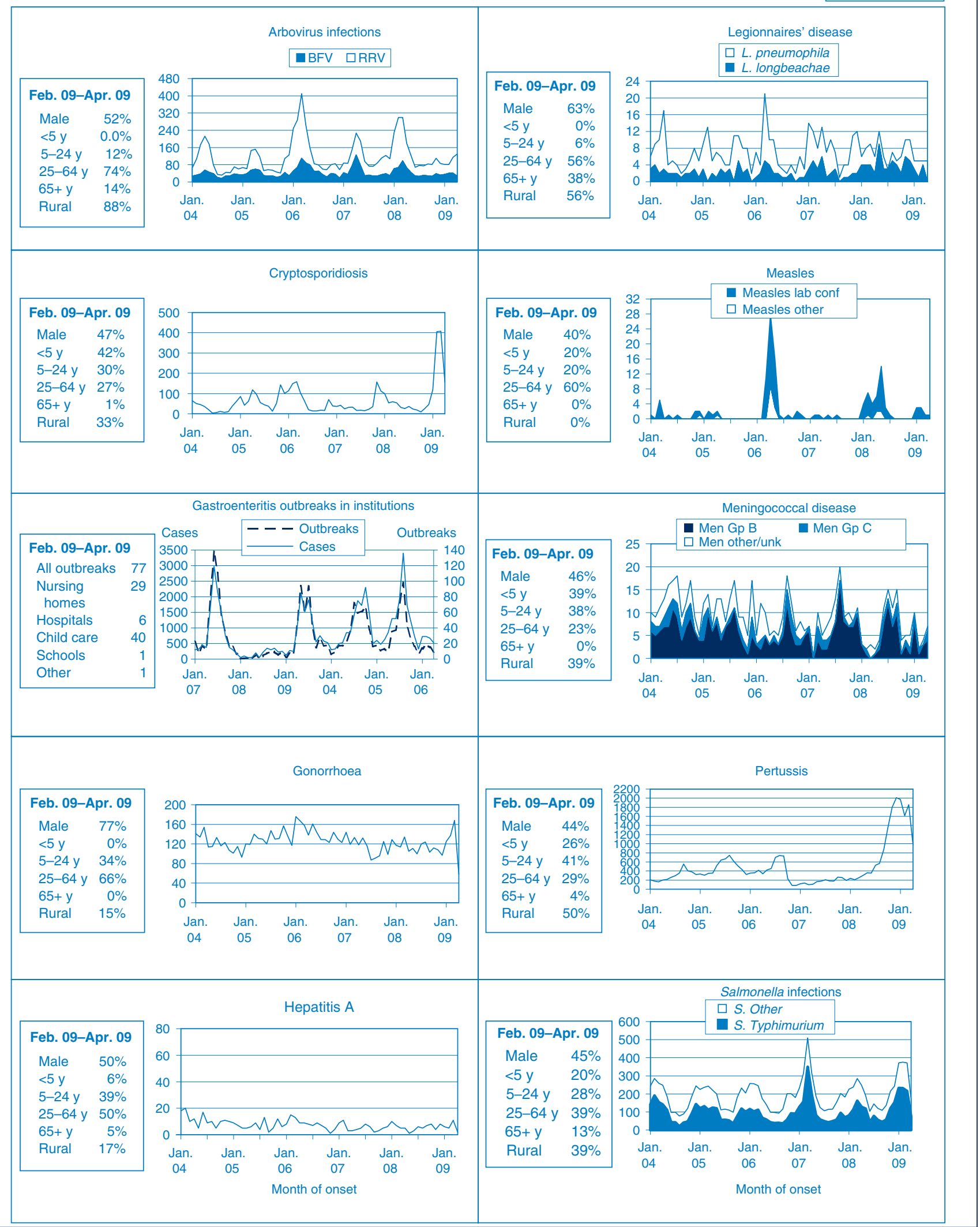




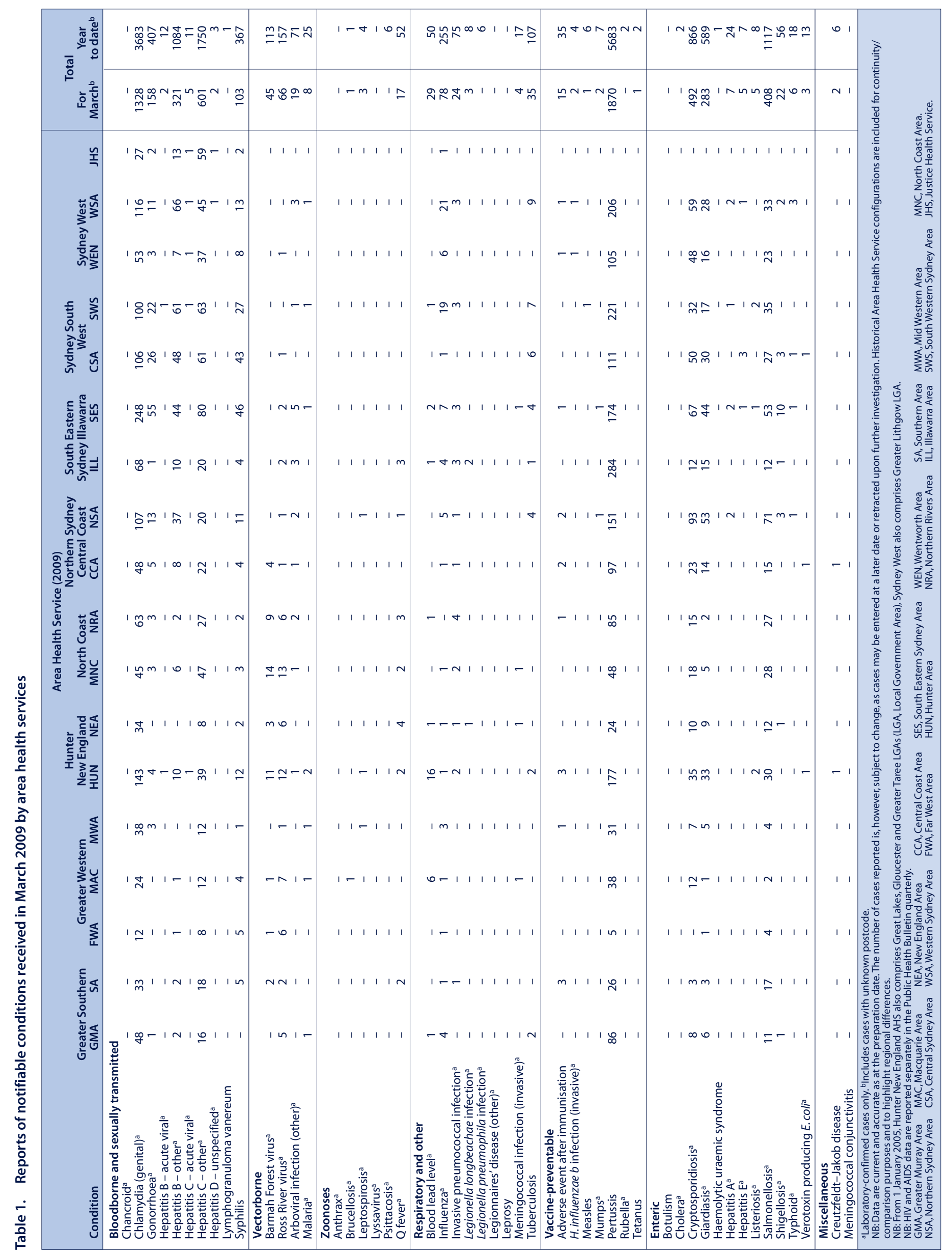




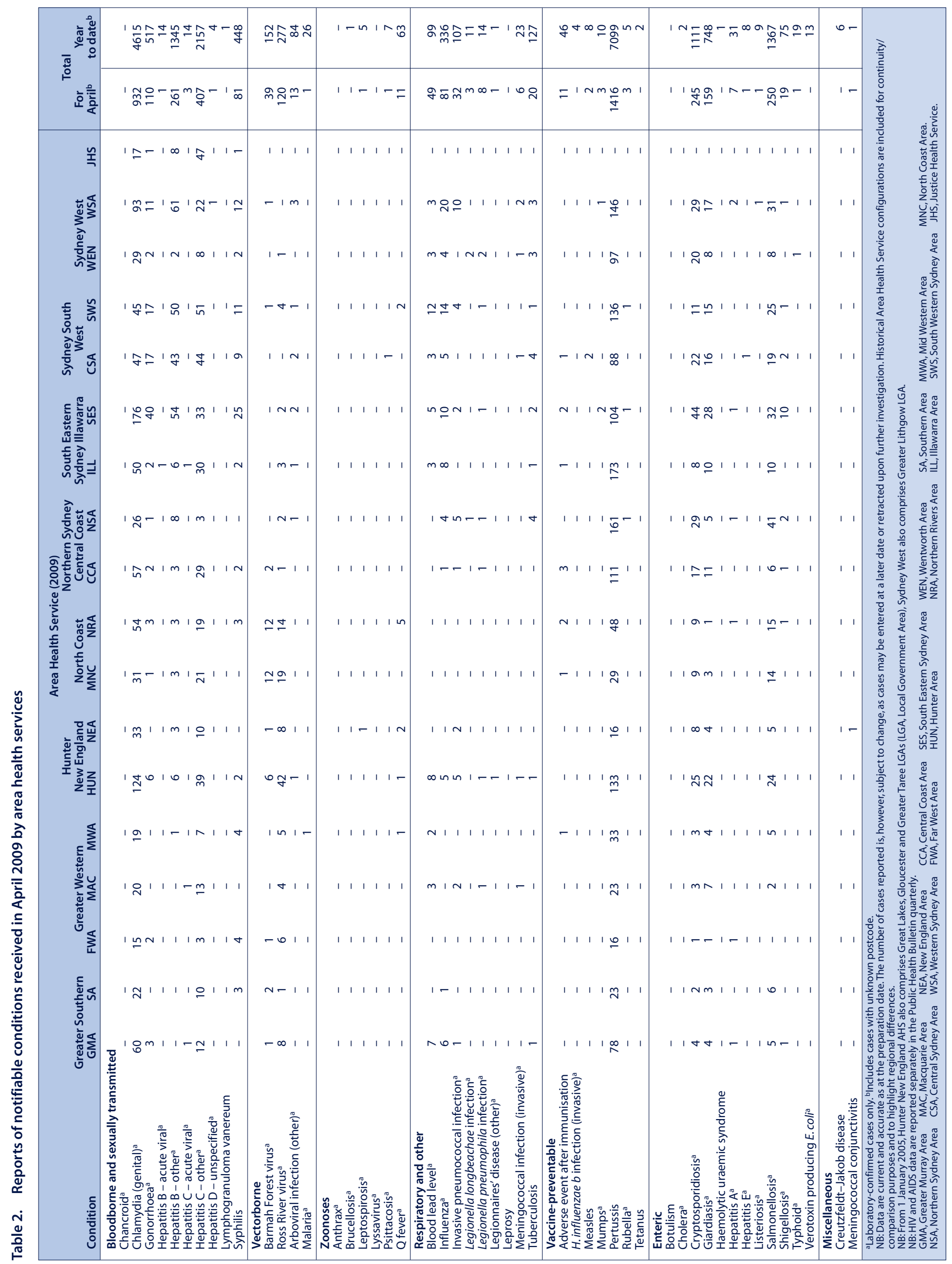




\section{Contents}

77 A polio intervention in East African refugees to NSW Describes a public health intervention in Sydney in 2006 that resulted from potential exposure of a number of refugees to polio virus while in transit in Kenya.

Mitchell M. Smith and Sanjyot Vagholkar

81 The effectiveness of prophylaxis for measles contacts in NSW

Analyses the effectiveness of post-exposure prophylaxis in susceptible persons with known measles contact during a measles outbreak in Sydney in 2006.

Vicky Sheppeard, Bradley Forssman, Mark J. Ferson, Conrad Moreira, Sue Campbell-Lloyd, Dominic E. Dwyer and Jeremy M. McAnulty

86 Audit of post-exposure treatment to prevent lyssavirus infection in Sydney South West Area Health Service, 2005-2007

Describes the profile of individuals who received postexposure treatment to prevent lyssavirus infection in the Sydney South West Area Health Service between 2005 and 2007.

Adam T. Craig, Trish F. Mannes and Leena Gupta
90 Another opportunity for prevention: assessing alcohol use by women attending breast screening services in Lismore, NSW

Gauges the level of self-reported alcohol use among women accessing North Coast BreastScreen and discusses opportunities for preventive measures.

Michelle D. Daly, Megan E. Passey and Amanda J. Harvey

\section{Letters to the Editor}

93 Pertussis outbreaks in aged-care facilities

Mark J. Ferson, Peter W. Robertson

Anthony M. Brown and Ala'a Al-Murieb

\section{Bug Breakfast in the Bulletin}

95 Equine influenza

Paula J. Spokes, Ian Roth and Paul K. Armstrong

\section{Factsheet}

97 Influenza

\section{Communicable Diseases Report, NSW}

99 March and April 2009

\section{NSW PUBLIC HEALTH BULLETIN}

The NSW Public Health Bulletin is a peer-reviewed journal produced by the NSW Department of Health and indexed in Medline. It has a NSW focus, however, it aims to support the practice of public health more broadly.

\section{Editor}

Dawn Simpson

\section{Editorial correspondence}

Please address all correspondence and submissions to:

The Editor, NSW Public Health Bulletin Locked Mail Bag 961

North Sydney NSW 2059 Australia

Email:phbulletin@doh.health.nsw.gov.au

Telephone: +61 294245876

Fax: +61 293919232

\section{Submission of articles}

The Bulletin accepts proffered and commissioned articles along with short reports, on all aspects of public health. Articles should be 1500-2000 words, not including tables and figures, and should include an abstract of up to 100 words. Articles should follow the journal style and layout as closely as possible, as described in the Instructions to Authors. Articles should be emailed in a Word for Windows format to: phbulletin@doh.health.nsw.gov.au, and should be accompanied by a covering letter signed by all authors and a License to Publish. The Instructions to Authors, License to Publish and other useful information can be downloaded from the Bulletin website.

\section{Distribution}

The Bulletin is freely available from the Bulletin website. Copies of the current issue and back issues can be downloaded in both PDF and HTML formats. If you would like to be notified when new issues of the Bulletin are available online, subscribe to the early alert email system at the Bulletin website. The early alert email contains the contents of each new issue along with electronic links to the articles. To receive a printed copy of the Bulletin, subscribe online at the Bulletin website, or contact your local public health unit or the editorial office. eISSN 1834-8610

Website: www.publish.csiro.au/journals/phb Copyright $\odot 2009$ NSW Department of Health 